\title{
Brain function monitoring during off-pump cardiac surgery: a case
} report

\author{
Paolo Zanatta*1, Enrico Bosco ${ }^{1}$, Piero Di Pasquale², Agarwal Nivedita ${ }^{3}$, \\ Carlo Valfrè ${ }^{4}$ and Carlo Sorbara ${ }^{1}$
}

\begin{abstract}
Address: ${ }^{1}$ Anesthesia and Intensive Care Department, Treviso Regional Hospital, Piazzale Ospedale ${ }^{\circ} 1,31100$, Treviso, Italy, ${ }^{2}$ Anesthesia and Intensive Care Department, Rovigo Hospital, Viale 3 Martiri, 140, 45100, Rovigo, Italy, ${ }^{3}$ Neurology Department, Udine University Hospital, Santa Maria della Misericordia, Piazzale Santa Maria della Misericordia, 15 33100, Udine, Italy and ${ }^{4}$ Cardiovascular Desease Departement, Treviso Regional Hospital, Piazzale Ospedale ${ }^{\circ} 1,31100$, Treviso, Italy

Email: Paolo Zanatta* - pzanatta@mac.com; Enrico Bosco - ebosco@ulss.tv.it; Piero Di Pasquale - piero.dipasquale@tele2.it; Agarwal Nivedita - agarwal.nivedita@aoud.sanita.fvg.it; Carlo Valfrè - cvalfre@ulss.tv.it; Carlo Sorbara - csorbara@ulss.tv.it

* Corresponding author
\end{abstract}

Published: 15 August 2008

Cases Journal 2008, I:94 doi:10.1186/1757-1626-1-94

This article is available from: http://www.casesjournal.com/content///I/94

(C) 2008 Zanatta et al; licensee BioMed Central Ltd.

This is an Open Access article distributed under the terms of the Creative Commons Attribution License (http://creativecommons.org/licenses/by/2.0), which permits unrestricted use, distribution, and reproduction in any medium, provided the original work is properly cited.
Received: 18 June 2008

Accepted: 15 August 2008

\begin{abstract}
Background: Early postoperative stroke is an adverse syndrome after coronary bypass surgery. This report focuses on overcoming of cerebral ischemia as a result of haemodynamic instability during heart enucleation in off-pump procedure.

Case presentation: A 67 year old male patient, Caucasian race, with a body mass index of 28 , had a recent non-Q posterolateral myocardial infarction one month before and recurrent instable angina. His past history includes an uncontrolled hypertension, dyslipidemia, insulin dependent diabetes mellitus, epiaortic vessel stenosis. The patient was scheduled for an off-pump procedure and monitored with bilateral somatosensory evoked potentials, whose alteration signalled the decrement of the cardiac index during operation.

The somatosensory evoked potentials appeared when the blood pressure was increased with a pharmacological treatment.

Conclusion: During the off-pump coronary bypass surgery, a lower cardiac index, predisposes patients, with multiple stroke risk factors, to a reduction of the cerebral blood flow. Intraoperative somatosensory evoked potentials monitoring provides informations about the functional status of somatosensory cortex to reverse effects of brain ischemia.
\end{abstract}

\section{Background}

Postoperative stroke is a serious adverse event after coronary artery bypass surgery (CABG) and may be increased in patients with multiple risk factors for cerebral ischemia [1]. The off-pump procedure can reduce neurological complications avoiding the use of cardiopulmonary bypass and aortic manipulation [2,3]. However, this can cause hemodynamic instability related to a low cardiac output, low vascular resistance, preload variation and a physical obstruction of the venous return, with subsequent hypotension [4].

Reduced cerebral perfusion can be further aggravated in patients with significant carotid stenosis [5]. 
Intraoperative neurophysiological assistance provides information on the brain's functional reserve allowing the anesthesiologist and the surgeon to perform a neuroprotective strategy $[6,7]$.

\section{Case presentation}

A 67 year old male patient, Caucasian race, body mass index of 28, with two-vessel disease not amenable to angioplasty, was scheduled for an off-pump procedure, consisting in a left internal mammary artery graft on anterior descending coronary artery and venous grafts on the obtuse marginal. His medical history included one month before, a non-Q posterolateral myocardial infarction and recurrent instable angina; complete occlusion of the right internal carotid and left vertebral artery and 50\% stenosis of the left internal carotid artery; uncontrolled hypertension; dyslipidemia, and insulin dependent diabetes mellitus complicated with lower limb sensory neuropathy. Seven years ago, the patient had suffered a stroke because of closing right carotid artery, without clinical effects.

Brain Magnetic Resonance Imaging Scan diagnosed a suffering circle of Willis. The preoperative echocardiography revealed a mild posterolateral hypokinetic wall movement with normal ejection fraction. The chest X-ray showed moderate aortosclerosis of the ascending aorta.
The neurologic examination was negative with the exception of altered tactile sensibility of the legs bilaterally.

During operation we used the Pressure Invasive Continuos Cardiac Output technology to monitor in continuous, the cardiac output. Epicardial echocardiography was obtained to exclude any atheromatous plaques in the ascending aorta.

SEPs (somatosensory evoked potentials) from median nerve by electrical stimulation were recorded in continuous, after general anesthesia induction. The median nerve were bilaterally stimulated with subdermal needle electrods at the wrist. The recording electrods were placed at the homolateral Erb's point and at the $\mathrm{C}^{\prime} / \mathrm{C} 4$ ' at opposite side the stimulation site. The stimulation rate was $3.7 \mathrm{~Hz}$. After a baseline obtained with a 300 stimulus average, the ongoing average was obtained with 30 stimulus.

\section{Results}

The SEPs and the hemodynamic parameters did not change until the end of the first graft.

During the heart displacement to perform the second coronary anastomosis, the cardiac index (CI) markedly decreased (from 2.9 to $1.8 \mathrm{l} / \mathrm{min} / \mathrm{m}^{2}$ ), without arterial

Table I: SEP, hemodynamic and respiratory variable recordings and the neuroprotection strategy during the operative steps.

\begin{tabular}{|c|c|c|c|c|c|c|c|c|}
\hline & \multicolumn{2}{|c|}{$\begin{array}{l}\text { Post anaesthesia } \\
\text { induction }\end{array}$} & \multicolumn{2}{|c|}{ Heart enucleation } & \multicolumn{2}{|l|}{$\begin{array}{l}\text { "Anestesiologist } \\
\text { reaction" }\end{array}$} & \multicolumn{2}{|c|}{ End surgery } \\
\hline & Right & Left & Right & Left & Right & Left & Right & Left \\
\hline N20/P25 latency (msec) & 22.67 & 23.83 & - & $25.54 \pm 0.08$ & $23.86 \pm 0.13$ & $25.52 \pm 0.08$ & 25.15 & 23.35 \\
\hline N20/P25 amplitude (uV) & $1.922 \pm 0.09$ & $2.51 \pm 0.13$ & 0.02 & $1.83 \pm 0.007$ & $1.03 \pm 0.3$ & $2 \pm 0.04$ & $1.67 \pm 0.03$ & $1.68 \pm 0.01$ \\
\hline CF (pulse/min) & 80 & & 60 & & 65 & & 65 & \\
\hline $\mathrm{SAP}(\mathrm{mmHg})$ & 135 & & 130 & & 173 & & 146 & \\
\hline $\mathrm{MAP}(\mathrm{mmHg})$ & 84 & & 91 & & 114 & & 95 & \\
\hline $\mathrm{DAP}(\mathrm{mmHg})$ & 58 & & 70 & & 76 & & 67 & \\
\hline CVP $(\mathrm{mmHg})$ & 18 & & 24 & & 27 & & 18 & \\
\hline $\mathrm{Cl}\left(\mathrm{I} / \mathrm{min} / \mathrm{m}^{2}\right)$ & 2.9 & & 1.8 & & 1.8 & & 2.6 & \\
\hline SVRI (dyn.sec.m²/cm5) & 1820 & & 2977 & & 3866 & & 2369 & \\
\hline $\mathrm{PaCO}_{2}(\mathrm{mmHg})$ & 38 & & 39 & & 40 & & 40.5 & \\
\hline $\mathrm{SaO}_{2}(\mathrm{mmHg})$ & 100 & & 100 & & 100 & & 100 & \\
\hline $\mathrm{T}\left({ }^{\circ} \mathrm{C}\right)$ & 36.2 & & 35 & & 34.8 & & 35 & \\
\hline
\end{tabular}

\section{neuro-protection}

Norephi $(\mathrm{mcg} / \mathrm{Kg} / \mathrm{h})$

MAC (Et isoflurane)

$\mathrm{FiO} 2(\%)$

$\mathrm{Hb}(\mathrm{g} / \mathrm{dl})$

Volume load (liter)

$\begin{array}{ll}- & - \\ 0.5 & 0.5 \\ 50 & 50 \\ 10 & 10\end{array}$

-
0.5
50
10

0.08

1

100

12

0.5 HES. +0.5 blood

N20/P25 = cortical SEP, CF = cardiac frequency, SAP = systolic arterial pressure, MAP = mean arterial pressure, DAP = diastolic arterial pressure, $\mathrm{CVP}=$ central venous pressure, $\mathrm{Cl}=$ cardiac index, $\mathrm{SVRI}=$ systemic vascular resistence index, $\mathrm{PaCO}^{2}=$ arterial pressure of $\mathrm{CO}^{2}, \mathrm{SaO}^{2}=\mathrm{oxygen}$ saturation, Norephi $=$ norephinefrine, $\mathrm{MAC}=$ minimum alveolar concentration, $\mathrm{FiO}^{2}=$ inspiratory fraction of oxygen, $\mathrm{Hb}=$ haemoglobin, $\mathrm{T}=$ temperature, $\mathrm{HES}=$ Hydroxyethylstarch 
pressure variation and the right SEP disappeared (Table $1)$, (Figure 1). The left SEP amplitude was reduced by $30 \%$. No variation were noted on the Erb's recording.

After 10 minutes, with establishment of a neuroprotection strategy, the right SEP reappeared (Table 1) (Figure 1). The systolic blood pressure was increased to $173 \mathrm{mmHg}$ using norepinephrine intravenous boluses of $15 \mathrm{mcg}$. The inspiratory fraction of oxygen was set at $100 \%$ until the end of last anastomosis. The volemia was also increased by administering $500 \mathrm{ml}$ of Hydroxyethylstarch and two packed red cells. Furthermore, the brain metabolism was reduced by increased the end tidal minimal alveolar concentration (MAC) of isoflurane until 1. The CI didn't change during this time.

A norepinephrine infusion of $0.08 \mathrm{mcg} / \mathrm{Kg} / \mathrm{h}$ was then started and maintained until the end of the surgery (Table 1 ). When the heart was replaced in the pericardium the CI went up to $2.4 \mathrm{l} / \mathrm{min} / \mathrm{m}^{2}$.

At end surgery the cortical SEP amplitude in the right and left hemispheres was respectively 13\% and 33\% lower from baseline values which are still in the normal range [7]. No significative variation on the SEP latency were noted during the case.
The patient was estubated after 5 hours without any neurologic impairment.

\section{Discussion}

Cerebral ischemia in off-pump cardiac surgery occurs due to brain hypoperfusion induced by heart dislocation and possible macroembolic events during partial clamping of the aorta. In our patient, the SEP amplitude disappeared after heart enucleation because of reduced brain oxygen delivery. This variation allowed us to increase Cerebral Blood Flow and arterial concentration of oxygen by enhancing the haemoglobin concentration and the inspiratory fraction of oxygen. A bolus of norepinephrine was administered to increase cerebral perfusion pressure. Brain vascular resistances were reduced by increasing the MAC of isoflurane that reduced also the brain oxygen consumption. The increasing dose of volatile agent did not influence the ability to use SEP to monitor the effect of treatment but produced an attenuation of wave amplitude recorded until the end of surgery like few authors have reported [8].

In literature there is no papers about the use of SEPs for monitoring the brain function in high risk patients for cerebral ischemia submitted to off pump cardiac surgery

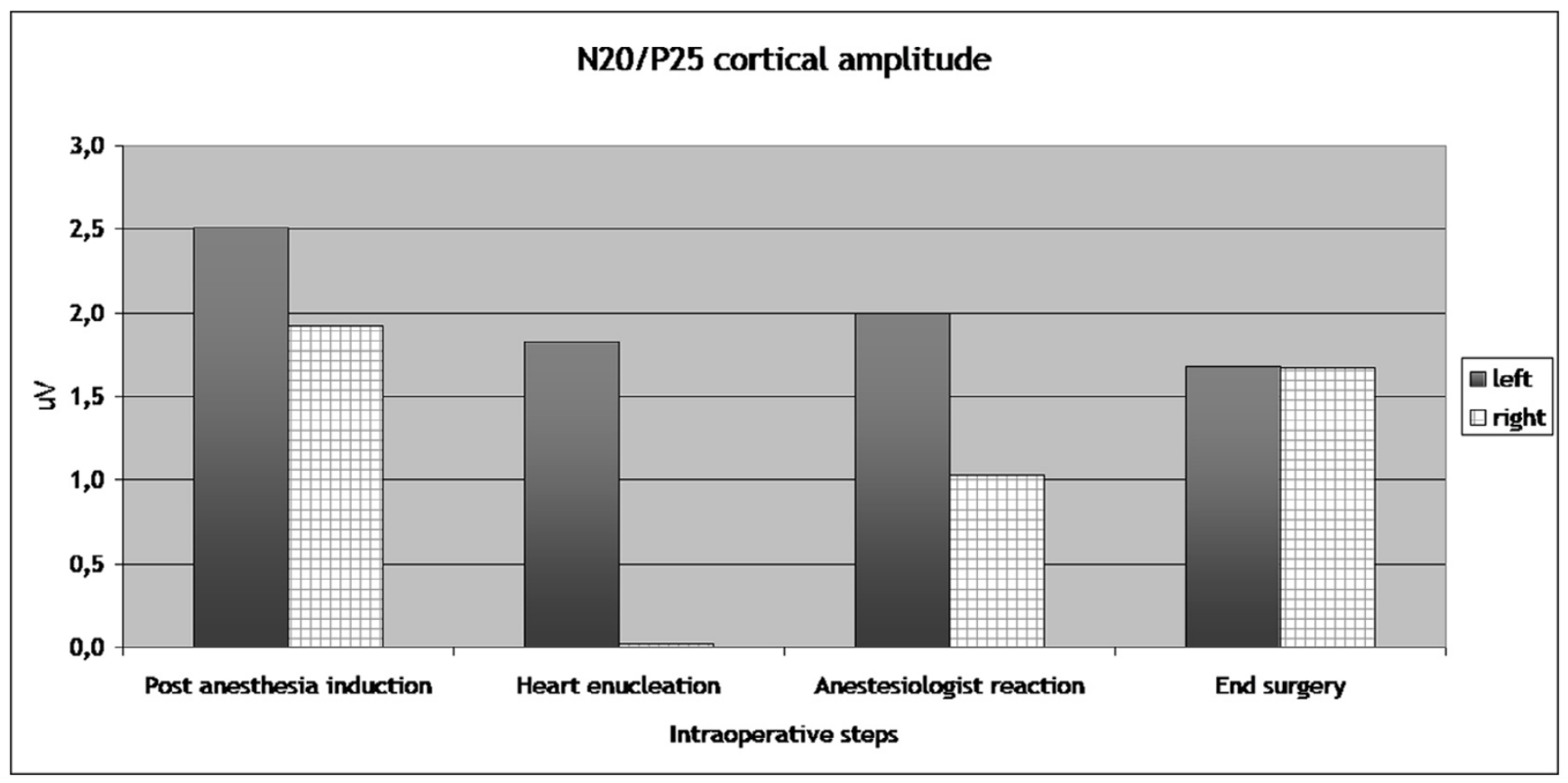

\section{Figure I}

SEP (N20/P25) amplitude variation during the intraoperative steps. The right SEP disappeared when the heart is enucleated. Both SEPs have a non significant wave amplitude attenuation at the end of surgery. N20/P25 complex is the most important scalp-recorded cortical component that has a negative peak about 20 msec followed by a positive peak at about 25 msec. 
while there is one paper about the use of electroencephalogram in this setting [6].

The SEPs are a reliable method to monitor brain function during surgery and they present some advantages in respect to the Electroencephalogram, because they are particularly resistant to the anaesthesia, moderate hypothermia and enviromental electrical interference because of averaging [7].

We chose SEP because the brain generators of the cortical SEP (N20/P25) are situated within the middle cerebral artery territory which covers $60 \%$ of the brain. Thus, continuous monitoring of the cortical SEP not only provides information on the integrity of the Central Nervous System, but also indirectly on the level of cerebral flow necessary to maintain minimal cortical function.

A $50 \%$ reduction of the N20 amplitude and a $20 \%$ increase in its latency is considered a clear sign of brain ischemia, in absence of ischemic arm, global hypoxia and bolus of anesthetic drugs [7].

\section{Conclusion}

The low cardiac index produced by the heart enucleation during the CABG off-pump, increases the risk of cerebral hypoperfusion. Intraoperative SEP monitoring seems to be a reliable method to perform a neuroprotection strategy and prevent cortical damage also in off pump coronary artery bypass grafting. Further studies are necessary to confirm this hypothesis.

\section{Abbreviations}

CABG: Coronary artery bypass surgery; SEPs: Somatosensory evoked potentials; CI: Cardiac index; MAC: Minimum alveolar concentration; N20/P25: Cortical SEP.

\section{Competing interests}

The authors declare that they have no competing interests.

\section{Authors' contributions}

PZ conceived the work, collected and analyzed the data and write the article. EB analyzed the data. PDP analyzed the data. AN helped to write the article. VC conceived the work and analized the data. SC analized the data. All authors read and approved the final manuscript.

\section{Consent}

Written informed consent was obtained from the patient for publication of this case report and accompanying images. A copy of the written consent is available for review by the Editor-in-Chief of this journal.

\section{References}

I. Puskas JD, Winston AD, Wright CE, Gott JP, Brown WM 3rd, Craver JM, Jones EL, Guyton RA, Wientraub WS: Stroke after coronary operation: incidence, correlates, outcome, and cost. Ann Thorac Surg 2000, 69:1053-6.

2. Zamvar V, Williams D, Hall J, Payne N, Cann C, Young K, S Karthikeyan, Dunne J: Assessment of neurocognitive impairment after off-pump and on pump techniques for coronary artery bypass graft surgery: prospective randomised controlled trial. BM] 2002, 325(7375): $\mid 268$.

3. Mishra M, Malhotra R, Karlekar A: Propensity case-matched analysis of off-pump coronary artery bypass grafting in patients with atheromatous aorta. Ann Thorac Surg 2006, 82(2):608-14.

4. Chassot PG, Linden P Van Der, Zaugg M, Mueller XM, Spahn DR: Off pump coronary artery bypass surgery: physiology and anaesthetic management. BrJ Anaesth 2004, 92:400-13.

5. Brener BJ, Brief DK, Alpert J, Goldenkranz RJ, Parsonnet V: The risk of stroke in patients with asimptomatic carotid stenosis undergoing cardiac surgery: a follow up study. J Vasc Surg 1987, 5:269-79.

6. Berry MF, McGarvey ML, Zeng L, Woo YJ: Neurological monitoring and off-pump surgery in a very high-risk stroke patient. Ann Thorac Surg 2005, 80:2372-4.

7. Florance G, Guerit JM, Gueguen B: Electroencephalography and somatosensory evoked potentials to prevent cerebral ischemia in the operating theatre. Neurophysiologie Clinique 2004, 34: 17-32.

8. Porkkala $T$, Jäntti $V$, Kaukinen $S$, Häkkinen $V$ : Somatosensory evoked potentials during isoflurane anaesthesia. Acta Anaesthesiol Scand 1994, 38(3):206-10.
Publish with BioMed Central and every scientist can read your work free of charge

"BioMed Central will be the most significant development for disseminating the results of biomedical research in our lifetime. " Sir Paul Nurse, Cancer Research UK

Your research papers will be:

- available free of charge to the entire biomedical community

- peer reviewed and published immediately upon acceptance

- cited in PubMed and archived on PubMed Central

- yours - you keep the copyright

Submit your manuscript here:

http://www.biomedcentral.com/info/publishing_adv.asp
BioMedcentral 